\title{
Exigências nutricionais de cálcio e fósforo de codornas de corte em crescimento
}

\author{
Ronaldo Martins da Silva ${ }^{1}$, Antonio Claudio Furlan ${ }^{2}$, Ana Paula Silva Ton ${ }^{3}$, Elias Nunes \\ Martins $^{2}$, Carina Scherer ${ }^{3}$, Alice Eiko Murakami ${ }^{2}$
}

\footnotetext{
1 Programa de Pós-graduação em Zootecnia - UEM, Maringá, PR.

2 Departamento de Zootecnia - UEM, Maringá, PR.

${ }^{3}$ Doutoranda do Programa de Pós-graduação em Zootecnia - UEM, Maringá, PR.
}

RESUMO - Foram conduzidos três experimentos com o objetivo de estimar as exigências nutricionais de cálcio e fósforo disponível de codornas de corte em crescimento. No experimento 1 (1-14 dias de idade), 1.250 codornas de corte foram distribuídas em esquema fatorial $5 \times 5$ (níveis de cálcio $=0,65 ; 0,76 ; 0,87 ; 0,98$ e $1,09 \% \times$ níveis de fósforo = 0,12; 0,22; 0,32; 0,42 e 0,52\%), totalizando 25 tratamentos com duas repetições e 25 aves por unidade experimental. Os níveis de cálcio não influenciaram o desempenho das aves, mas os níveis de fósforo afetaram de forma quadrática o peso corporal, o ganho de peso e a densitometria óptica, com estimativa de exigência em 0,41\%. No experimento 2 (15-35 dias de idade), 1.500 codornas de corte foram distribuídas em esquema fatorial $5 \times 5$ (níveis de cálcio = 0,61;0,71;0,81;0,91 e 1,01\% × níveis de fósforo $=0,29 ; 0,34 ; 0,39 ; 0,44$ e $0,49 \%$ ), totalizando 25 tratamentos com duas repetições e 30 aves por unidade experimental. Os níveis de fósforo influenciaram de forma quadrática a densitometria óptica, e a exigência de fósforo foi estimada em $0,41 \%$. No experimento 3, realizado para avaliação do balanço de cálcio e fósforo (28-35 dias de idade), constatou-se efeito linear crescente dos níveis de cálcio das dietas sobre a ingestão e excreção de cálcio e nenhum efeito dos níveis de cálcio sobre o desempenho nas fases de 1 a 14 e de 15 a 35 dias de idade. Os níveis 0,65\% e 0,61\% são suficientes para atender às exigências nutricionais de cordornas de corte nas fases de 1 a 14 e de 15 a 35 dias de idade, e o nível de 0,41\% de fósforo disponível é o que promove máximo desempenho dessas aves.

Palavras-chave: balanço, densitometria óptica, desempenho, osso

\section{Calcium and phosphorus requirements of finishing meat quail}

ABSTRACT - Three experiments were carried out to estimate the calcium and phosphorus requirements of meat quail. In the first experiment (1-14 days of age), 1,250 meat quails were placed in a $5 \times 5$ factorial arrangement (calcium levels = $0.65,0.76,0.87,0.98$ and $1.09 \% \times$ phosphorus levels $=0.12,0.22,0.32,0.42$ and $0.52 \%$ ), totaling 25 treatments, with two replications of 25 birds per experimental unit. The different calcium levels did not affect bird performance. Body weight, weight gain and optic density were influenced in a quadratic form by phosphorus levels and the phosphorus requirement was estimated at $0.41 \%$. The levels of $0.65 \%$ calcium and $0.41 \%$ phosphorus in diet were enough to meet the requirement of initial phase meat quail. In the second experiment (15-35 days of age), 1,500 meat quails were placed in a $5 \times 5$ factorial arrangement (calcium levels $=0.61,0.71,0.81,0.91$ and $1.01 \% \times$ phosphorus levels $=0.29,0.34,0.39,0.44$ and $0.49 \%$ ), totaling 25 treatments, with two replications of 30 birds per experimental unit. Differences were not observed of the calcium and phosphorus levels on bird performance. Optic density was influenced in a quadratic form by phosphorus levels and the phosphorus requirement was estimated at $0.41 \%$. In the third experiment, to assess the calcium and phosphorus balance (28-35 days of age), a linear effect was observed on the calcium intake and excretion with the increase in the calcium levels in the diets. The levels of $0.61 \%$ calcium and $0.41 \%$ phosphorus in the diet were enough to meet the requirement of finishing meat quail. The calcium levels did not affect bird performance at 1-14 and 15-35 days of age, showing, respectively, 0.65 and $0.61 \%$ calcium levels were enough to meet the of meat quail requirement. The estimate of $0.41 \%$ phosphorus promoted performance of finishing meat quail.

Key Words: balance, bone, optic density, performance 


\section{Introdução}

A procura do mercado consumidor atual por carne de qualidade e outros fatores, como rápido crescimento dos animais, precocidade na produção e maturidade sexual, alta produtividade, baixo investimento inicial e o rápido retorno financeiro, tornam a coturnicultura de corte atividade altamente promissora no País (Pinto et al., 2002).

A codorna é uma excelente alternativa para a alimentação humana, pois pode ser utilizada tanto para produção de ovos como para produção de carne, que é aceita universalmente por ser um produto de excelente qualidade e rica em aminoácidos essenciais (Fugikura, 2002).

Embora já existam informações nacionais sobre requerimentos de codornas japonesas de postura (Murakami \& Ariki, 1998), as informações disponíveis sobre codornas de corte são escassas, conflitantes e obtidas de literatura estrangeira, em condições totalmente diversas das vigentes no Brasil (Oliveira, 2001).

Para elaboração de programa nutricional para codornas de corte, o nutricionista baseia-se nas recomendações das tabelas do NRC (1994) com exigência de cálcio e fósforo disponível de 0,80 e $0,30 \%$ respectivamente, que são elaboradas para atender às exigências de codornas japonesas, cujo peso corporal é menor que o de codornas de corte.

A determinação das corretas exigências nutricionais é de grande importância para todas as espécies avícolas, uma vez que a dieta é, talvez, o principal fator ambiental que determina se as aves vão crescer até seu potencial genético máximo. Nas codornas de corte, esse aspecto assume uma importância ainda maior, pois, na fase de 1 a 28 dias de vida, têm seu peso aumentado em cerca de 16 vezes (Oliveira et al., 2002).

Entre os nutrientes, o cálcio e fósforo são os minerais mais importantes na nutrição animal, por serem necessários não apenas para ótima taxa de crescimento, mas também por serem os principais formadores da matriz mineral, contribuindo com 95\% (Gomes et al., 2004).

O cálcio e o fósforo devem estar disponíveis na dieta em quantidades e proporções adequadas para atender às necessidades dos animais, considerando a idade, a raça, a categoria ou a situação fisiológica e o sistema de produção adotado (Gomes et al., 2004). Com base nessas considerações, objetivou-se com este trabalho estimar as exigências nutricionais de cálcio e fósforo disponível para máximo desempenho de codornas de corte de 1 a 14 e de 15 a 35 dias de idade.

\section{Material e Métodos}

Os experimentos foram realizados no Setor de Coturnicultura da Fazenda Experimental de Iguatemi, na Universidade Estadual de Maringá - UEM.

No experimento 1 (1 a 14 dias), 1.250 aves de 1 dia de idade não-sexadas foram pesadas e alojadas de forma uniforme em galpão convencional dividido em 50 boxes de $2,5 \mathrm{~m}^{2}$, com cobertura de telha de fibra amianto, piso de terra batida e paredes laterais de alvenaria com telas de arame até o telhado providas de cortinas laterais. Foi utilizada cama de palha de arroz sobre o piso.

O delineamento experimental utilizado foi o inteiramente casualizado, em esquema fatorial $5 \times 5$ (níveis de cálcio $=$ 0,$65 ; 0,76 ; 0,87 ; 0,98$ e $1,09 \% \times$ níveis de fósforo $=0,12 ; 0,22 ;$ $0,32 ; 0,42$ e $0,52 \%)$, totalizando 25 tratamentos com 2 repetições e 25 codornas por unidade experimental.

As rações experimentais (Tabela 1 ) foram formuladas à base de milho e farelo de soja, conforme as tabelas de Rostagno et al. (2005), e os teores de cálcio e fósforo foram obtidos modificando as quantidades de calcário, fosfato bicálcico e a areia lavada, utilizada como inerte.

Em cada unidade experimental (boxe), foram utilizados círculos de proteção e uma campânula como fonte de aquecimento para os pintinhos; a cama foi forrada com um papelão até o sétimo dia de idade. Para avaliação de desempenho zootécnico (consumo de ração, peso vivo, ganho de peso e conversão alimentar), as rações e as aves foram pesadas semanalmente até o $14^{\circ}$ dia.

No experimento 2 (15 - 35 dias), utilizaram-se 1.500 aves alojadas em um galpão convencional dividido em 50 boxes de $2,5 \mathrm{~m}^{2}$, com cobertura de telha de fibra amianto, piso de terra batida e paredes laterais de alvenaria com telas de arame até o telhado providas de cortinas laterais. Foi utilizada cama de palha de arroz sobre o piso.

Até os 14 dias de idade, todas as aves receberam a mesma alimentação (Tabela 2). As rações experimentais (Tabela 3) foram formuladas à base de milho e farelo de soja e os diferentes teores de cálcio e fósforo das rações foram obtidos modificando as quantidades de calcário, fosfato bicálcico e a areia lavada utilizada como inerte. Aos 15 dias de idade, as aves, não-sexadas, foram pesadas, homogeneizadas e distribuídas nas unidades experimentais. Ao final do experimento (35 dias), foram realizadas a contagem e a determinação da proporção de macho e fêmea em cada unidade experimental.

O delineamento experimental utilizado foi o inteiramente casualizado, em esquema fatorial $5 \times 5$ (níveis de cálcio $=$ 0,$61 ; 0,71 ; 0,81 ; 0,91$ e 1,01\% × níveis de fósforo = 0,29; 0,34; 
Tabela 1 - Composição da ração experimental fornecida a codornas de corte no período de 1 a 14 dias de idade

\begin{tabular}{|c|c|}
\hline Ingrediente & \% da ração \\
\hline Milho grão & 48,60 \\
\hline Farelo soja $45 \%$ & 43,00 \\
\hline Óleo de soja & 2,90 \\
\hline Suplemento vitamínico ${ }^{1}$ & 0,40 \\
\hline Sal comum & 0,40 \\
\hline Suplemento mineral ${ }^{2}$ & 0,07 \\
\hline DL-metionina & 0,39 \\
\hline L-lisina $\mathrm{HCl}$ & 0,30 \\
\hline Antioxidante ${ }^{3}$ & 0,01 \\
\hline (Inerte + fosfato bicálcico + calcário) & 3,93 \\
\hline \multicolumn{2}{|l|}{ Composição nutricional } \\
\hline Proteína bruta (\%) & 24,00 \\
\hline Energia metabolizável (kcal/kg) & 2.900 \\
\hline Fibra bruta (\%) & 3,49 \\
\hline Lisina digestível (\%) & 1,43 \\
\hline Metionina+cistina digestível (\%) & 1,02 \\
\hline Extrato etéreo (\%) & 5,15 \\
\hline \multicolumn{2}{|c|}{ 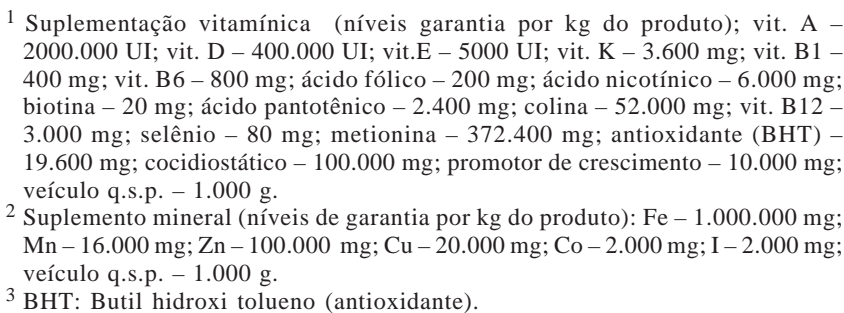 } \\
\hline
\end{tabular}

0,39; 0,44 e $0,49 \%$ ), totalizando 25 tratamentos com 2 repetições e 30 codornas por unidade experimental.

Para avaliação de desempenho zootécnico (consumo de ração, peso vivo, ganho de peso, conversão alimentar e rendimento de carcaça), as rações e as aves foram pesadas no início e no final do experimento, aos 35 dias.

Aos 35 dias foram colhidas, aleatoriamente, 2 aves por unidade experimental, perfazendo um total de 4 aves/ tratamento, para avaliação do rendimento de carcaça. Para determinação do rendimento de carcaça, os animais foram mantidos por 8 horas em jejum e sacrificados por decapitação entre os ossos occipital e atlas.

As aves foram sangradas por 2 minutos em cone adaptado ao abate de codornas e escaldadas por 20 a 40 segundos em temperatura de 53 a $55^{\circ} \mathrm{C}$. A depena foi manual e as aves foram evisceradas por meio de corte abdominal realizado com tesoura. Para o cálculo de rendimento de carcaça, foi considerado o peso da carcaça eviscerada, sem os pés e cabeça, em relação ao peso vivo, o qual foi obtido individualmente antes do abate das aves.

As rações experimentais foram formuladas para atender o mínimo das exigências das codornas em fase inicial de crescimento (NRC, 1994), exceto de cálcio e fósforo. Durante os dois períodos experimentais, as rações e a água foram
Tabela 2 - Composição da ração experimental fornecida a codornas de corte no período de 15 a 35 dias de idade

\begin{tabular}{|c|c|}
\hline Ingrediente & $(\%)$ \\
\hline Milho grão & 48,60 \\
\hline Farelo soja $45 \%$ & 43,00 \\
\hline Óleo de soja & 2,90 \\
\hline Suplemento vitamínico ${ }^{1}$ & 0,40 \\
\hline Sal comum & 0,40 \\
\hline Fosfato bicálcico & 1,59 \\
\hline Calcário & 0,37 \\
\hline Antioxidante ${ }^{3}$ & 0,01 \\
\hline Suplemento mineral ${ }^{2}$ & 0,07 \\
\hline DL-metionina & 0,39 \\
\hline L-lisina $\mathrm{HCl}$ & 0,30 \\
\hline Inerte (areia lavada) & 1,97 \\
\hline \multicolumn{2}{|l|}{ Composição nutricional } \\
\hline Proteína bruta (\%) & 24,00 \\
\hline Energia metabolizável (kcal/kg) & 2.900 \\
\hline Fibra bruta $(\%)$ & 3,49 \\
\hline Lisina digestível (\%) & 1,43 \\
\hline Metionina+cistina digestível (\%) & 1,02 \\
\hline Extrato etéreo (\%) & 5,15 \\
\hline Cálcio (\%) & 0,65 \\
\hline Fósforo (\%) & 0,41 \\
\hline \multicolumn{2}{|c|}{ 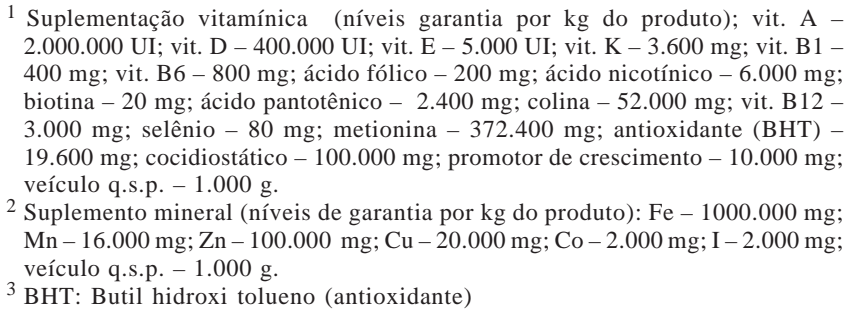 } \\
\hline
\end{tabular}

fornecidas à vontade para as aves e os dados de temperatura foram coletados no início da manhã e no final da tarde, utilizando-se termômetros de máxima e mínima. O programa de iluminação foi contínuo, com 24 horas de luz, durante todo o período experimental.

Para avaliação dos parâmetros ósseos, ao final dos experimentos (14 e 35 dias de idade) foram sacrificadas duas aves por unidade experimental, por decapitação entre os ossos occipital e atlas, para coleta do fêmur esquerdo. Os ossos coletados foram congelados $\left(-18^{\circ} \mathrm{C}\right)$ até o inícío das análises, quando foram submetidos ao descongelamento e à retirada dos tecidos envolventes (tecido muscular aderido) com auxílio de tesouras e pinças.

Os ossos frescos foram mergulhados em éter de petróleo durante 24 horas, para o desengorduramento, e secos em estufa de ventilação forçada a $55^{\circ} \mathrm{C}$ por 72 horas. A determinação da densidade óptica radiográfica foi realizada na Clínica de Odontologia do Hospital Universitário de Maringá.

Em uma primeira etapa, as peças ósseas foram colocadas sob o filme (marca Kodak Intraoral E-Speed Film, size 2, tipo periapical), todas na mesma posição, e radiografadas em aparelho de raios-x odontológico Dabi Atlante, modelo: Spectro 70X, Classe I - Tipo B - Comum, calibrado com 
distância foco-filme de $25 \mathrm{~cm}$, ajustado para $70 \mathrm{kVp}$ e tempo de exposição de 0,3 segundos. As radiografias foram reveladas manualmente, utilizando-se em todas as peças um padrão de revelação; para isso, foram separadas em grupos de 10 unidades e colocadas na solução reveladora por um minuto. Em seguida, as peças ósseas foram lavadas em águas corrente por um período de três minutos, colocadas em solução fixadora por dez minutos e novamente lavadas em água corrente por mais 20 minutos, quando foram levadas a estufa de ventilação forçada a $40^{\circ} \mathrm{C}_{-}$até a secagem total.

Na segunda etapa, as radiografias foram digitalizadas utilizando-se escâner com resolução de 600 DPI (Dots Per Inch $=$ pontos por polegada), $50 \%$ de brilho, $50 \%$ de contraste, $\mathrm{W}-1,58, \mathrm{H}-1,84, \mathrm{X}-0,00$ e $\mathrm{y}-0,05$ e gravadas em arquivos com extensão JPG progressivo.

A terceira etapa consistiu da leitura das radiografias para determinação da densidade das peças ósseas. Para isso foi utilizado o software "Adobe Photoshop 8.0", que possui um recurso (Histograma) para análise da densidade radiográfica da área selecionada, a qual se encontra distribuída em uma escala de cores, mais especificamente o cinza, que possui 256 tons, de modo que o valor 0 (zero) representa o preto e o valor 256 representa o branco.

Tabela 3 - Composição da ração experimental fornecida a codornas de corte no período de 28 a 35 dias de idade

\begin{tabular}{|c|c|}
\hline Ingrediente & $(\%)$ \\
\hline Milho grão & 48,60 \\
\hline Farelo soja $45 \%$ & 43,04 \\
\hline Óleo de soja & 2,90 \\
\hline Suplemento vitamínico ${ }^{1}$ & 0,40 \\
\hline Sal comum & 0,40 \\
\hline Suplemento mineral ${ }^{2}$ & 0,07 \\
\hline DL-metionina & 0,39 \\
\hline L-lisina $\mathrm{HCl}$ & 0,26 \\
\hline Antioxidante ${ }^{3}$ & 0,01 \\
\hline (Inerte + fosfato bicálcico + calcário) & 3,93 \\
\hline Total & 100,00 \\
\hline \multicolumn{2}{|l|}{ Valores calculados } \\
\hline Proteína bruta (\%) & 24,00 \\
\hline Energia metabolizável (kcal/kg) & 2.900 \\
\hline Fibra bruta (\%) & 3,49 \\
\hline Lisina digestível (\%) & 1,26 \\
\hline Metionina+cistina digestível (\%) & 1,02 \\
\hline Extrato etéreo (\%) & 5,15 \\
\hline \multicolumn{2}{|c|}{ 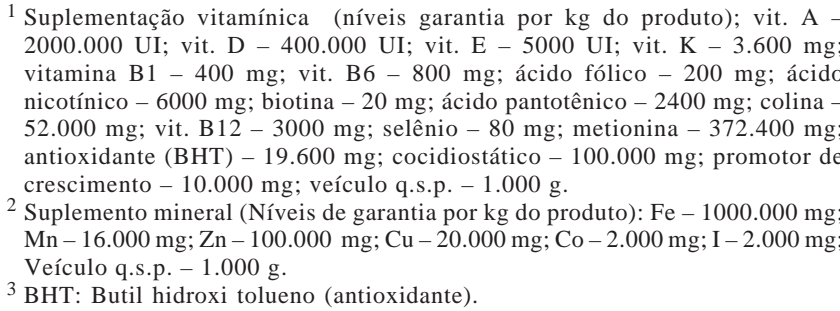 } \\
\hline
\end{tabular}

Como referencial radiográfico, utilizou-se uma escala de alumínio de 10 degraus com 1 mm de espessura entre um degrau e outro. A determinação da densidade óssea foi realizada na área mais central possível, por ser a mesma área que, no ensaio de resistência, recebeu a aplicação da força necessária à quebra.

Os dados obtidos em valores de cinza foram convertidos em valores relativos à espessura da escala de alumínio. Para a conversão, foi realizada a setorização da curva densiométrica característica pelo programa computacional $\mathrm{Excel}^{\circledR}$, que fornecia a expressão matemática que melhor se ajustava aos pontos experimentais contidos no intervalo.

As análises de resistência foram realizadas em uma máquina universal de ensaios mecânicos, marca EMIC ${ }^{\circledR}$ modelo DL3000, de modo que os dados eram coletados por um computador diretamente da máquina, por meio do Programa Computacional Tesc ${ }^{\circledR}$, e os valores expressos em Newton (N).

As peças ósseas foram posicionadas em apoios da região das epífises, deixando as peças sem apoio na região central. A posição escolhida foi a antero-posterior para evitar que ossos se deslocassem no momento da quebra. A força foi aplicada na região central, sempre no mesmo ponto, em todos os ossos. A velocidade de descida da sonda/aplicação da força foi a mesma $(5 \mathrm{~mm} / \mathrm{s})$ para todos os ossos e foi mensurada a força aplicada no momento anterior à ruptura do osso. A carga utilizada foi de $1500 \mathrm{~N}$ para todas as amostras, entretanto, as distâncias entre os apoios foram de 18 e 22 mm para os ossos de 14 e 35 dias, respectivamente.

Após o ensaio para a determinação da resistência óssea, os fêmures esquerdos foram triturados e secos em estufa de ventilação forçada, pesados em balança analítica $(0,0001 \mathrm{~g})$, e secos em estufa a $105^{\circ} \mathrm{C}$ por 12 horas para determinação do teor de cálcio e fósforo dos ossos.

Dos 28 aos 35 dias de idade, foi conduzido o ensaio de balanço de cálcio e fósforo, utilizando-se 90 codornas de corte (Coturnix coturnix sp). As aves foram retiradas das unidades experimentais, pesadas e alojadas em gaiolas de arame galvanizado $(20 \mathrm{~cm}$ de largura $\times 33 \mathrm{~cm}$ de profundidade $\times 25 \mathrm{~cm}$ de altura) com bebedouros tipo nipple e comedouro tipo calha.

O delineamento experimental utilizado foi o inteiramente casualizado, em esquema fatorial $3 \times 3$ (níveis de cálcio = 0,$61 ; 0,81 ;$ e $1,01 \% \times$ níveis de fósforo = 0,29; 0,$39 ;$ e 0,49\%), totalizando nove tratamentos com duas repetições e cinco codornas por unidade experimental.

As aves e as rações foram pesadas no início e ao final do período experimental. Utilizou-se óxido férrico (2\%) na ração como marcador do início e do final de coleta. As 
gaiolas foram forradas com plástico e as coletas foram realizadas a cada 12 horas, durante todo o período experimental. As excretas foram acondicionadas em sacos plásticos, devidamente identificadas por repetição e armazenadas em congelador depois de cada coleta. No final do período experimental, foram determinadas as quantidades de ração consumida e de excretas produzidas por repetição. As excretas foram descongeladas, reunidas por parcela, homogeneizadas, pesadas e mantidas em estufa de ventilação forçada a $55^{\circ} \mathrm{C}$ por 72 horas. Após a pré-secagem, foram moídas e analisadas quanto aos teores de cálcio e fósforo.

A análise estatística dos dados foi realizada por meio do programa Sistema para Análises Estatísticas - SAEG (1997), da Universidade Federal de Viçosa, e as estimativas de exigências de cálcio e fósforo foram obtidas pelo modelo quadrático.

\section{Resultados e Discussão}

Não foram observadas interações $(\mathrm{P}>0,05)$ entre os níveis de cálcio e fósforo disponível para as variáveis de desempenho (Tabela 4). Os níveis de cálcio não influenciaram o desempenho $(\mathrm{P}>0,05)$ das codornas de corte aos 14 dias de idade, o que indica que $0,65 \%$ de cálcio foi suficiente para atender à exigência nutricional das aves nesta fase de criação. Esses resultados confirmam os obtidos por Reddy et al. (1980), que, trabalhando com codornas japonesas em crescimento (1 a 21 dias), estimaram exigência de $0,60 \%$ de cálcio.

Os níveis de fósforo das rações influenciaram de forma quadrática $(\mathrm{P}<0,05)$ o peso corporal e o ganho de peso aos 14 dias, com estimativa de exigência para o máximo peso corporal (PC) e ganho de peso (GP) de $0,41 \%$, como representado pelas equações: $\mathrm{PC}=55,8287+81,66 \mathrm{P}-99,79 \mathrm{P}^{2}$ e GP $=47,4369+82,3588 \mathrm{P}-100,879 \mathrm{P}^{2}$. Esse resultado está de acordo com o obtido por Yakout (2004), que sugeriu a utilização de níveis de fósforo de 0,35 a $0,41 \%$ para codornas japonesas em fase inicial de criação (1 - 21 dias). No entanto, Reddy et al. (1980) estimaram as exigências de fósforo disponível em 0,30\%.

Brandão (2005) estimou exigências de 0,48\% de fósforo disponível para codornas japonesas machos na fase inicial de criação ( 1 a 21 dias) e verificaram que níveis superiores a $0,50 \%$ não provocaram alterações no desempenho das aves. Tanto a deficiência quanto o excesso de fósforo disponível foram prejudiciais ao desenvolvimento das aves, o que está de acordo com sugestões de Shirivastav et al. (2002) de que a deficiência de fósforo pode reduzir o desempenho das aves, principalmente pela diminuição no consumo de ração, provavelmente em virtude da severa redução na síntese e liberação de hormônios de crescimento e hormônios da tireoide, principalmente triiodotironina.

Não houve efeito dos níveis de cálcio e de fósforo na conversão alimentar $(\mathrm{P}>0,05)$ aos 14 dias de idade. O teor de cálcio dos ossos (CO) nessa idade aumentou linearmente

Tabela 4 - Desempenho de codornas de corte de 1 a 14 dias de idade alimentadas com rações com diversos níveis de cálcio e fósforo

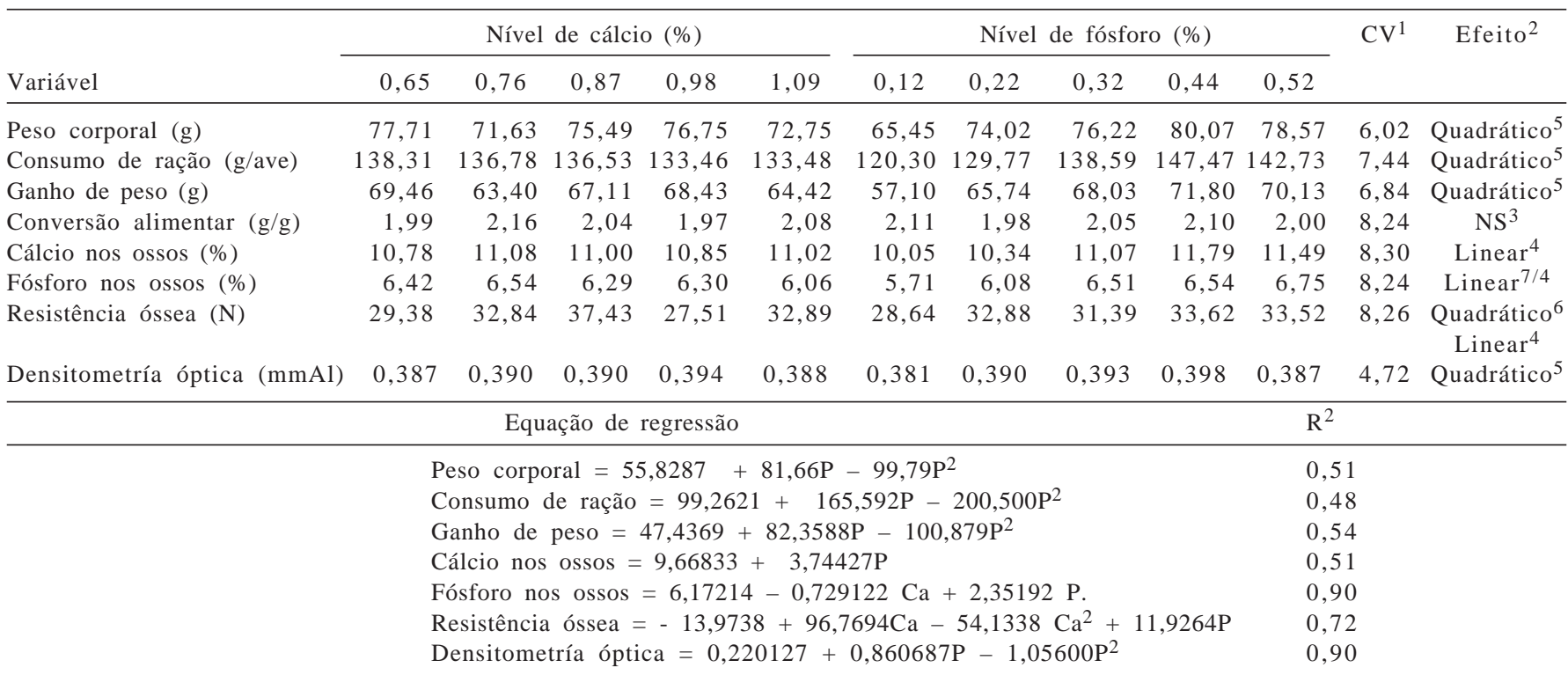

${ }^{1}$ Coeficiente de variação; ${ }^{2}$ Análise de regressão; ${ }^{3} \mathrm{NS}$ - Não-significativo; ${ }^{4}$ Efeito linear do P; ${ }^{5}$ Efeito quadrático do P; ${ }^{6}$ Efeito quadrático dos nível de cálcio; ${ }^{7}$ Efeito linear do cálcio. 
$(\mathrm{P}<0,05)$ com os níveis de fósforo, como demonstrado na equação: $\mathrm{CO}=9,66833+3,74427 \mathrm{P}$. Isso provavelmente está relacionado à absorção de fósforo, que depende da orção de cálcio. Segundo Bertechini (2006), sem um nível ideal de cálcio na dieta, não tem como ocorrer máxima absorção do fósforo.

O teor de fósforo dos ossos (FO) reduziu linearmente $(\mathrm{P}<0,05)$ com o aumento dos níveis de cálcio e aumentou linearmente $(\mathrm{P}<0,05)$ com o aumento nos níveis de fósforo disponível, como mostrado pela equação: $\mathrm{FO}=6,17214$ 0,729122 Ca + 2,35192 P. De acordo com Bertechini (2006), conforme aumentam os níveis de cálcio da dieta, ocorre redução da biossíntese da proteína transportadora de cálcio ao nível duodenal e diminuição da eficiência absortiva do mineral, assim, a melhor eficiência de utilização desse nutriente ocorre com os níveis mais baixos.

A resistência óssea (RO) aos 14 dias de idade foi influenciada de forma quadrática $(\mathrm{P}<0,05)$ pelo aumento nos níveis de cálcio das rações $(\mathrm{RO}=-13,9738$ + 96,7694Ca $\left.-54,1338 \mathrm{Ca}^{2}+11,9264 \mathrm{P}\right)$, com estimativa de $0,89 \%$ para máxima resistência. O aumento do nível de fósforo disponível nas rações promoveu melhoria linear $(\mathrm{P}<0,05)$ na resistência óssea. Reis et al. (2005) relataram comportamento semelhante para a resistência à quebra de fêmur de frangos de corte avaliados com diferentes níveis de fósforo aos 21 dias de idade.

Os resultados deste experimento corroboram observações feitas por Vieites et al. (2004) de que a exigência nutricional para melhorar o desempenho das aves é inferior à exigência para aumentar a resistência óssea. Segundo Tablante et al. (2003), a perda óssea somente comprometerá a resistência quando houver deficiência prolongada dos minerais.
Foi observado efeito quadrático $(\mathrm{P}<0,05)$ dos níveis de fósforo sobre a densidade óptica (DO), com ponto de máximo em 0,41\%, como demonstrado pela equação: DO = $0,220127+0,860687 \mathrm{P}-1,05600 \mathrm{P}^{2}$.

A utilização de radiografias tem sido um parâmetro biofísico de grande importância para determinação quantidade de minerais nos ossos das aves (Louzada et al., 1998). A densitometria óptica radiográfica tem sido cada vez mais utilizada por pesquisadores por ser um método preciso e confiável, que permite avaliar de forma mais segura a mineralização óssea em comparação aos demais parâmetros químicos. Dessa forma, pode-se inferir de forma mais correta sobre o conteúdo mineral de ossos (Vulcano, 2000).

Não foram observadas interações $(\mathrm{P}>0,05)$ entre os níveis de cálcio e de fósforo disponível (Tabela 5) para o ganho de peso, o consumo de ração e a conversão alimentar das codornas de corte em crescimento (15 a 35 dias de idade). Os resultados observados nesta pesquisa confirmam os encontrados por Pizzolante (2000), que não detectou diferenças significativas no desempenho de frangos de corte de 22-42 dias ao testarem diferentes níveis de cálcio, e os de Brandão (2005), que também não verificou efeitos dos níveis crescentes de fósforo disponível (0,15-1,05\%) em codornas japonesas em fase final de crescimento (35 dias de idade).

Os resultados indicam que as exigências de cálcio são menores que as estabelecidas no NRC (1994) (0,80\%). O fato de não terem sido observadas diferenças nas características de desempenho pode estar relacionado à possível mobilização do cálcio do tecido ósseo, que poderia estar sendo utilizado para suprir os requerimentos desse mineral pelas aves (Fialho et al., 1992).

Tabela 5 - Consumo de ração, ganho de peso, conversão alimentar, rendimento de carcaça, teores de cálcio e fósforo no osso, resistência óssea e densitometria óptica de codornas de corte de 15 a 35 dias de idade alimentadas com rações com diversos níveis de cálcio e fósforo

\begin{tabular}{|c|c|c|c|c|c|c|c|c|c|c|c|c|}
\hline \multirow[b]{2}{*}{ Variável } & \multicolumn{5}{|c|}{ Nível de cálcio (\%) } & \multicolumn{5}{|c|}{ Nível de fósforo (\%) } & \multirow[t]{2}{*}{$\mathrm{CV}^{1}$} & \multirow[t]{2}{*}{ Efeito ${ }^{2}$} \\
\hline & 0,61 & 0,71 & 0,81 & 0,91 & 1,01 & 0,29 & 0,34 & 0,39 & 0,44 & 0,49 & & \\
\hline Consumo de ração (g/ave) & 415,73 & 409,97 & 407,54 & 416,48 & 397,91 & 398,93 & 405,51 & 410,64 & 417,15 & 415,41 & 6,19 & $\mathrm{NS}^{3}$ \\
\hline Ganho de peso (g) & 150,85 & 148,48 & 149,03 & 154,12 & 145,99 & 147,43 & 149,93 & 149,24 & 152,18 & 149,69 & 3,27 & $\mathrm{NS}^{3}$ \\
\hline Convesão alimentar (g/g) & 2,76 & 2,76 & 2,73 & 2,70 & 2,72 & 2,71 & 2,70 & 2,75 & 2,74 & 2,72 & 5,02 & $\mathrm{NS}^{3}$ \\
\hline Rendimento de carcaça (\%) & 71,59 & 72,30 & 72,13 & 72,85 & 71,77 & 70,57 & 72,12 & 72,75 & 73,63 & 71,60 & 4,72 & Quadrático ${ }^{4}$ \\
\hline Cálcio no osso (\%) & 13,59 & 12,89 & 13,75 & 15,18 & 14,88 & 14,16 & 14,19 & 13,28 & 13,87 & 14,78 & 10,45 & $\begin{array}{c}\text { Quadrático } \\
\text { Linear }^{5}\end{array}$ \\
\hline Fósforo no osso (\%) & 5,56 & 5,40 & 5,78 & 5,52 & 5,84 & 5,51 & 5,48 & 5,85 & 5,72 & 5,53 & 10,15 & $\mathrm{NS}^{3}$ \\
\hline Resistêncio óssea (N) & 45,45 & 48,53 & 37,22 & 45,68 & 38,55 & 43,42 & 40,07 & 45,17 & 41,71 & 45,07 & 18,74 & $\mathrm{NS}^{3}$ \\
\hline Densitometria óptica (mmAl) & 0,517 & 0,521 & 0,520 & 0,524 & 0,518 & 0,511 & 0,520 & 0,523 & 0,527 & 0,517 & 3,55 & Quadrático $^{4}$ \\
\hline & \multicolumn{5}{|c|}{ Equação de regressão } & \multicolumn{7}{|c|}{$\mathrm{R}^{2}$} \\
\hline & \multicolumn{6}{|c|}{$\begin{array}{l}\mathrm{RC}=40,7234+159,227 \mathrm{P}-195,361 \mathrm{P}^{2} \\
\mathrm{CO}=25,295+4,877 \mathrm{Ca}-83,263 \mathrm{P}+110,253 \mathrm{P}^{2} \\
\mathrm{DO}=0,350126+0,860690 \mathrm{P}-1,05601 \mathrm{P}^{2}\end{array}$} & \multicolumn{4}{|c|}{$\begin{array}{l}0,90 \\
0,90 \\
0,90\end{array}$} & & \\
\hline
\end{tabular}

${ }^{1}$ Coeficiente de variação; ${ }^{2}$ Análise de regressão; ${ }^{3}$ NS - Não significativo; ${ }^{4}$ Efeito quadrático do P; ${ }^{5}$ Efeito linear do Ca. 
Os níveis de fósforo das rações influenciaram de forma quadrática $(\mathrm{P}<0,05)$ o rendimento de carcaça $(\mathrm{RC})$, com estimativa em $0,41 \%$, como demonstrado pela equação: $\mathrm{RC}=40,7234+159,227 \mathrm{P}-195,361 \mathrm{P}^{2}$. Em relação a esta variável, os resultados encontrados diferem dos obtidos por Brandão (2005), que, trabalhando com codornas japonesas fêmeas, não verificou efeito dos níveis de fósforo disponível com aves aos 21 dias de idade. Para aves aos 45 dias de idade, o autor estimou exigência de 0,59\% de fósforo disponível para melhor rendimento de carcaça.

Os valores de rendimento da carcaça de codornas de corte está de acordo com os encontrados por Otutumi (2006), que verificou rendimento em torno de $70 \%$. Não houve efeito $(\mathrm{P}>0,05)$ no teor de fósforo nos ossos das codornas de corte de 15 a 35 dias de idade.

O teor de cálcio nos ossos (CO) aos 35 dias de idade foi influenciado de forma quadrática $(\mathrm{P}<0,05)$ pelo aumento dos níveis de fósforo das rações $(\mathrm{CO}=25,295+4,877 \mathrm{Ca}-$ 83,263 P + 110,253 $\mathrm{P}^{2}$ ), com estimativa para máxima deposição de cálcio em $0,37 \%$ de fósforo disponível. Com o aumento dos níveis de cálcio das rações, verificou-se aumento linear $(\mathrm{P}<0,05)$ na quantidade de cálcio nos ossos.

Esses resultados são semelhantes aos encontrados por Vargas Jr. et al. (2003), que observaram maiores teores de cálcio em ossos de aves alimentadas com rações contendo maiores níveis de cálcio. Simões (2005) relata que o cálcio é o mineral metabolicamente mais ativo, por isso, quando a ingestão é suficiente ou excessiva, a calcitonina aumenta a eliminação de cálcio pelos rins, estimulando a deposição nos ossos e reduzindo a absorção intestinal. Esse autor relatou ainda que as aves jovens apresentam melhor equilíbrio de sedimentação óssea.

Inadequada relação cálcio e fósforo na dieta, pela carência de um ou de outro, pode limitar a disponibilidade de ambos e ocasionar desequilíbrio na homeostase mineral, além de desenvolvimento inapropriado dos ossos das aves, ou seja, calcificação anormal dos ossos (Cabral, 1999).

Assim, a influência da suplementação dietética de cálcio sobre a deposição mineral e retenção de cálcio torna-se extremamente relevante, uma vez que os ossos são tecidos metabolicamente ativos e multifuncionais, que coordenam as atividades do metabolismo ósseo visando aumento em diâmetro e comprimento durante o crescimento das aves (Tardin, 1995).

Não houve efeito $(\mathrm{P}>0,05)$ na resistência a quebra nos ossos das codornas de corte de 15 a 35 dias de idade. Rath (2000) afirmou que a resistência óssea não está condicionada apenas ao nível de minerais, mas também a estrutura orgânica do osso. Os autores explicaram que o osso é um tecido complexo composto pelas matrizes orgânicas e inorgânicas que oferecem suporte e resistência mecânica. A matriz inorgânica, principalmente hidroxiapatita, fornece a resistência à compressão e a matriz orgânica, composta predominantemente por colágeno, oferece resistência à tensão e serve de suporte para a incorporação da matriz orgânica.

Os níveis de fósforo das rações influenciaram de forma quadrática $(\mathrm{P}<0,05)$ a densitometria óptica aos 35 dias. De acordo com o modelo de regressão quadrática, a exigência de fósforo foi estimada em $0,41 \%$, como demonstrado pela equação: $\mathrm{DO}=0,350126+0,860690 \mathrm{P}-1,05601 \mathrm{P}^{2}$.

A utilização de radiografias tem sido um parâmetro biofísico de grande importância para determinação da quantidade de minerais nos ossos das aves (Louzada et al., 1998). A densitometria óptica radiográfica vem sendo cada vez mais utilizada por pesquisadores por ser um método preciso e confiável, que permite avaliar de forma mais segura a mineralização óssea em comparação aos parâmetros químicos, dessa maneira pode-se inferir de forma mais correta sobre o conteúdo de mineral de ossos (Vulcano, 2000).

Não houve efeito $(\mathrm{P}>0,05)$ do fósforo e cálcio da ração sobre os níveis de fósforo ingerido (FI) e fósforo excretado e o coeficiente de digestibilidade do fósforo (CDF) das codornas de corte em crescimento (28 a 35 dias) (Tabela 6).

Observou-se aumento linear $(\mathrm{P}<0,05)$ na ingestão e excreção de cálcio (CE) com o aumento dos níveis de cálcio nas dietas de codornas de corte no período de 28 a 35 dias $(\mathrm{CE}=-0,309328+1,13845 \mathrm{Ca}$ eCI $=-1,72444+9,84955 \mathrm{Ca})$.

Tabela 6 - Valores médios de cálcio ingerido e excretado, coeficiente de digestibilidade do cálcio, fósforo ingerido e excretado e coeficiente de digestibilidade do fósforo em codornas de corte de 28 a 35 dias de idade

\begin{tabular}{|c|c|c|c|c|c|c|c|c|}
\hline \multirow[b]{2}{*}{ Variável } & \multicolumn{3}{|c|}{ Nível de cálcio (\%) } & \multicolumn{3}{|c|}{ Nível de fósforo (\%) } & \multirow[t]{2}{*}{$\mathrm{CV}^{1}$} & \multirow[t]{2}{*}{ Efeito $^{2}$} \\
\hline & 0,61 & 0,81 & 1,01 & 0,29 & 0,39 & 0,49 & & \\
\hline Cálcio ingerido (g) & 4,12 & 6,58 & 8,06 & 6,80 & 5,96 & 6,60 & 0,78 & Linear ${ }^{4}$ \\
\hline Cálcio excretado (g) & 0,39 & 0,60 & 0,85 & 0,65 & 0,57 & 0,62 & 0,66 & Linear $^{4}$ \\
\hline Coeficiente de digestibilidade do cálcio (\%) & 90,41 & 90,97 & 89,35 & 90,50 & 90,69 & 89,54 & 0,45 & Linear ${ }^{5}$ \\
\hline Fósforo ingerido (g) & 2,61 & 3,12 & 3,09 & 2,42 & 2,79 & 3,60 & 0,51 & $\mathrm{NS}^{3}$ \\
\hline Fósforo excretado (g) & 0,30 & 0,36 & 0,38 & 0,32 & 0,34 & 0,38 & 0,48 & $\mathrm{NS}^{3}$ \\
\hline Coeficiente de digestibilidade do fósforo(\%) & 88,28 & 88,22 & 87,57 & 86,92 & 87,85 & 89,29 & 0,54 & $\mathrm{NS}^{3}$ \\
\hline
\end{tabular}

${ }^{1}$ Coeficiente de variação; ${ }^{2}$ Análise de regressão; ${ }^{3}$ NS - não-significativo; ${ }^{4}$ Efeito linear do cálcio; ${ }^{5}$ Efeito linear do fósforo. 
O cálcio ingerido é absorvido principalmente no intestino delgado, de forma passiva intercelular ou ativa via enterócitos, cuja eficiência absortiva varia com a fonte de cálcio, relação Ca:P e vitamina $\mathrm{D}$, o pH intestinal e o perfil fisiológico. Assim, quanto maior sua necessidade, maior a eficiência de absorção (McDowell, 1992). Oliveira \& Almeida (2004) cita que as codornas são animais altamente tolerantes as variações de cálcio e fósforo nas dietas e têm condições de excretar o excesso dos minerais.

Essa resposta na excreção do cálcio pode ser explicada pelo eficiente mecanismo de controle da homeostase de cálcio no organismo, controlado por hormônios que são capazes de induzir a uma diminuição drástica na absorção de cálcio nos intestinos e aumentar sua excreção pelos rins em resposta a excesso na ração, atingindo um equilíbrio dentro dos limites fisiológicos.

\section{Conclusões}

Os níveis de cálcio avaliados não influenciam o desempenho de codornas de corte nas fases de 1 a 14 e de 15 a 35 dias de idade. Os níveis 0,65 e 0,61\% de cálcio são suficientes para atender às exigências nutricionais das aves, e o 0,41\% de fósforo disponível promove máximo desempenho nas fases de 1 a 14 dias de idade e de 15 a 35 dias de idade. A máxima resistência óssea das codornas de corte de 1 a 14 dias de idade pode ser obtida com o nível de $0,89 \%$ de cálcio, portanto, a exigência nutricional para melhorar o desempenho das aves é inferior à exigência para aumentar a resistência óssea.

\section{Literatura Citada}

BERTECHINI, A.G. Nutrição de monogástricos. Lavras: Editora UFLA, 2006. p.179-181.

BRANDÃO, A.P. Exigências de cálcio e fósforo para codornas japonesas (Coturnix coturnix japonica) nas fases de reposição e postura. 2005. 147f. Tese (Doutorado em Zootecnia) - Universidade Federal da Paraíba, Areia, 2005.

CABRAL, G.H. Níveis de cálcio em rações para frango de corte. 1999. 83f. Dissertação (Doutorado em Zootecnia) Universidade Federal de Viçosa, Viçosa, MG, 1999.

FIALHO, E.T.; BARBOSA, H.D.; BELLAVER, C. et al. Avaliação nutricional de algumas fontes suplementação de cálcio para suínos - biodisponibilidade e desempenho. Revista Brasileira de Zootecnia, v.21, n.5, p.891-905, 1992.

FUGIKURA, W.S. Situação e perpectivas da coturnicultura no Brasil. SIMPÓSIO INTERNACIONAL DE COTURNICULTURA, 1. 2002, Lavras. Anais... Lavras: Universidade Federal de Lavras, 2002. p.10.

GOMES, P.C.; RUNHO, R.C.; ROSTAGNO, H.S. et al. Exigência de fósforo disponível para frangos de corte machos e fêmeas de 22 a 42 e de 43 a 53 dias de Idade. Revista Brasileira de Zootecnia, v.33, n.6, p.1734-1746, 2004 (supl. 1).

LOUZADA, M.J.Q.; PELÁ, C.A.; BELANGER, W.D. et al. Avaliações de densidade óssea em imagens radiográficas: estudo em peças ósseas de cães. RBE-Caderno de Engenharia Biomédica, v.14, n.1, p.47-64, 1998.

McDOWELL, L.R. Minerals in animal and human nutrition. New York: Academic Press, 1992. 523p.

MURAKAMI, A.E.; ARIKI, J. Produção de codornas japonesas Jaboticabal: FUNEP, 1998. 79p.

NATIONAL RESEARCH COUNCIL - NRC. Nutrient requirements of poultry. 9.ed. Washington, D.C.: National Academy of Sciences: 1994. 155p.

OLIVEIRA, E.G. Pontos críticos no manejo e nutrição de codornas. In: SIMPÓSIO SOBRE MANEJO E NUTRIÇÃO DE AVES E SUÍNOS E TECNOLOGIA DA PRODUÇÃO DE RAÇÕES, 2001, Campinas. Anais... Campinas: Colégio Brasileiro de Nutrição Animal, 2001. p.71-96.

OLIVEIRA, E.G.; ALMEIDA, M.I.M. Algumas informações sobre nutrição de codornas de corte. In: SIMPÓSIO INTERNACIONAL E CONGRESSO BRASILEIRO DE COTURNICULTURA, 2 e 1. 2004, Lavras. Palestras... Lavras: Universidade Federal de Lavras/NECTA, [2004]. p.53-66.

OLIVEIRA, N.T.E.; SILVA, M.A.; SOARES, R.T.R.N. et al. Exigência de proteína bruta e energia metabolizável para codornas japonesas criadas para a produção de carne. Revista Brasileira de Zootecnia, v.31, n.2, p.675-686, 2002.

OTUTUMI, L.K. Uso de probiótico para codornas de corte (Coturnix coturnix sp.). 2006. 80f. Tese (Doutorado em Zootecnia), Universidade Estadual de Maringá, Maringá, 2006.

PINTO, R.; FERREIRA, A.S.; ALBINO, L.F.T. et al. Níveis de proteína e energia para codornas japonesas em postura. Revista Brasileira de Zootecnia, v.31, n.4, p.1761-1770, 2002.

PIZZOLANTE, C.C. Estabilidade da fitase e sua utilização em frangos de corte. 2000. 121f. Tese (Doutorado em Zootecnia) - Universidade Federal de Lavras, Lavras, 2000.

RATH, N.C. Factors regulating bone maturity and strength in poultry. Poultry Science, v.79, p.1024-1032, 2000

REEDY, V.R.; SHRIVASTAV, A.K.; SADAGOPAN, V.R. Calcium and phosphorus requirements growing Japanese quail. British Poultry Science, v.21, p.385-387, 1980.

REIS, D.T.C.; BARBOSA, A.A.; MORAES, G.H.K. et al. Aspectos físicos, químicos e mecânicos de tíbias de frangos de corte machos e fêmeas. In: REUNIÃO ANUAL DA SOCIEDADE BRASILEIRA DE ZOOTECNIA, 42., 2005, Goiânia. Anais... Goiânia: Sociedade Brasileira de Zootecnia, [2005]. (CD-ROM).

ROSTAGNO, H.S.; ALBINO, L.F.T.; DONZELE, J.L. et al. Composição de alimentos e exigências nutricionais de aves e suínos (Tabelas brasileiras). Viçosa, MG: Universidade Federal de Viçosa, 2005. 141p.

SHRIVASTAV, A.K. Recentes avanços na nutrição de codornas japonesas. In: SIMPÓSIO INTERNACIONAL DE COTURNICULTURA - NOVOS CONCEITOS APLICADOS À PRODUÇÃO DE CODORNAS, 1., 2002, Lavras. Anais... Lavras: 2002. p.116-117.

SIMÕES, A.F. Influência da atividade física no tratamento da osteoporose. Disponível em: <http://www.cdof.com.br/fisio5.htm>. Acesso em: 7/12/2005.

TABLANTE, N.L.; ESTÉVEZ, I.E.; RUSSEK-COHEN, E. Effect of perches and stocking density on tibial dyschondroplasia and bone mineralization as measured by bone ash in broiler chickens. The Journal of Applied Poultry Research, v.12, p.53-59, 2003.

TARDIN, A.C. Visão nutricional dos problemas locomotores em frangos de corte. In: CONFERÊNCIA APINCO DE CIÊNCIA E TECNOLOGIA AVÍCOLAS, 1995, Santos. Palestra... Santos: Fundação APINCO de Ciência e Tecnologia Avícolas, 1995. p.71-85.

UNIVERSIDADE FEDERAL DE VIÇOSA - UFV. Sistema de análises estatísticas e genéticas - SAEG. Versão 5.0 . Viçosa, MG: 1997. 150p. (Manual do usuário).

VARGAS JR., R.; ALBINO, L.F.T.; ROSTAGNO, H.S. Níveis nutricionais de cálcio e fósforo disponível para aves de reposição 
leves e semipesadas de 0 a 6 semanas de idade. Revista Brasileira de Zootecnia, v.32, n.6, p.1919-1926, 2003 (supl. 2).

VIEITES, F.M.; MORAES, G.H.K.; ALBINO, L.F.T. et al. Balanço eletrolítico e níveis de proteína bruta sobre parâmetros sangüíneos e ósseos de frangos de corte aos 21 dias de idade. Revista Brasileira de Zootecnia, v.33, n.6, p.1520-1530, 2004.
VULCANO, L.C. Determinación de los valores normales de la densidad mineral ósea del carpo accesorio de equinos da la raza Puro Sangue Ingles por medio de la densitometría optica em imagen radiográfica. Imagen Veterinaria, v.3, n.6, p.237-240, 2000.

YAKOUT, H.M. Calcium and phosphorus requirements growing Japanese quail hens during the early production period. Egyptian Poultry Science Journal, v.23, p.617-628, 2004. 